\title{
O contador de histórias para crianças e jovens
}

Vera Teixeira de Aguiar I PUCRS

\begin{abstract}
Resumo: Erico Verissimo escreveu onze livros de literatura para crianças e jovens: em 1935, A vida de Joana d'Arc; em 1936, As aventuras do avião vermelho, Os três porquinhos pobres; Rosa Maria no castelo encantado $e$ Meu ABC; em 1937, As aventuras de Tibicuera; em 1938, O urso com música na barriga e, em 1939, A vida do elefante Basílio, Outra vez os três porquinhos, Aventuras no mundo da higiene $e$ Viagem à aurora do mundo. Essas obras constituem um projeto literário consciente, uma vez que o autor deixa claros seus objetivos junto ao público infanto-juvenil e acompanha suas constantes reediçôes. O Erico Verissimo tem por intenção formar e informar seus leitores e, para isso, vale-se da fantasia como meio de aproximação e sedução.

Palavras-chave: Erico Verissimo, Literatura Infantil e Juvenil, Formação de Leitores.
\end{abstract}

Quando examinamos a trajetória literária de nossos escritores, ao longo do século XX, não raro nos deparamos com obras escritas especialmente para as crianças e os jovens. São textos ocasionais, ao sabor de uma preocupação ou necessidade pontual, espaços na produção geral do artista. Com Erico Verissimo a situação é outra: diferentemente de muitos autores de seu tempo, não volta a atenção para esse público apenas depois 
de uma carreira literária sedimentada e madura. Ao contrário, os livros dedicados à infância e à juventude são produzidos na década de 30, quando o autor inaugura suas atividades. Nesse período, são escritas onze obras: em 1935, A vida de Joana d'Arc; em 1936, As aventuras do avião vermelbo, Os três porquinhos pobres; Rosa Maria no castelo encantado e Meu ABC; em 1937, As aventuras de Tibicuera; em 1938, O urso com música na barriga e, em 1939, A vida do elefante Basílio, Outra vez os três porquinhos, Aventuras no mundo da bigiene e Viagem à aurora do mundo.

Daí em diante, não produz textos novos, todavia, embora não retorne à literatura infanto-juvenil nas décadas seguintes, Erico acompanha de perto as constantes reedições de suas obras, ${ }^{1}$ assim depondo na apresentação da edição de 1965 de Gente e bichos: ${ }^{2}$

Escrevi estes contos no tempo em que os desenhos animados e coloridos de Walt Disney atingiam o seu apogeu e creio que não errei em afirmar que minhas histórias seguem o espírito "surrealista" dos "cartoons" daquele admirável criador de fantasias. Destinei minhas narrativas a crianças entre quatro e dez anos. Quero dizer, escrevi-as de tal modo que, se uma pessoa ler esses contos para crianças ainda não alfabetizadas, estas poderão compreendê-los.

A avaliação posterior que Erico Verissimo faz de seu trabalha revelanos um autor consciente do complexo literário, capaz de analisar todos os elementos que interferem no processo da produção e da recepção da literatura: intenções do escritor, características dos contos, influências de outras manifestações culturais de seu tempo, perfil do público, necessidade de adequação das obras às condições dos receptores, a fim de que a recepção se efetive. As palavras do autor demonstram o quanto está atento ao mundo das imagens, que começam a tomar conta dos produtos culturais destinados às crianças, o quanto busca a compreensão de seus leitores, tornando suas histórias acessíveis às mesmas. De certo modo, podemos dizer que ele está competindo

1. Apenas Meu ABC, escrito sob o pseudônimo de Nanquinote, e Aventuras no mundo da bigiene não foram reeditadas.

2. Gente e bichos reúne os contos infantis As aventuras do avião vermelho, Os três porquinhos pobres; Rosa Maria no castelo encantado, O urso com música na barriga e Outra vez os três porquinhos. 
com as figuras coloridas, isto é, oferecendo uma literatura que possa encantar tanto quanto o mundo ilustrado de Disney.

A literatura infanto-juvenil de Erico Verissimo, como vemos, nasce de um projeto bem definido, não se constituindo apenas de uma produção episódica e circunstancial. Está, nesse sentido, em consonância com a crescente efervescência da época, quando há expressivo aumento do "número de obras e o volume das edições, bem como o interesse das editoras, algumas delas, como a Melhoramentos e a Editora Brasil dedicadas quase que exclusivamente ao mercado constituído pela infância”. ${ }^{3}$ É, pois, nesse momento, que se fixa o gênero no Brasil, com Monteiro Lobato, seguido de autores como Viriato Correia, Luiz Jardim, Graciliano Ramos e tantos outros. Alguns, como dissemos, escrevendo esporadicamente para a infância, mesmo assim, ao buscarem atingir um novo público leitor, ajudam a consolidar o gênero. Seguramente, dois fatores contribuem para isso: a legitimação dos livros, através da consagração dos escritores no universo das letras, e a qualidade estética dos textos.

No esforço de garantir a maioridade da literatura infanto-juvenil em âmbito regional, Erico Verissimo está para o Rio Grande do Sul assim como Monteiro Lobato está para o Brasil. É claro que, no momento da escritura e da publicação das obras, o autor não é movido por um interesse assim pragmático, mas, sem dúvida nenhuma, anima-o a idéia de alargar o público, incluindo aí as crianças, futuras leitoras de seus romances. E ele está certo, pois o gosto pela leitura deve ser despertado nos primeiros anos, de forma lúdica e espontânea, o que implica a presença de livros e mais livros ao alcance dos pequenos. Contudo, até a chegada de Erico, o Estado conta com a produção literária para o público jovem formada, sobretudo, por adaptações de clássicos, traduções e algumas obras esparsas. Temos que levar em conta, ainda, o fato de que os textos, publicados principalmente no Rio de Janeiro, destinam-se muito mais aos leitores cariocas do que aos gaúchos. Com Erico, publicando toda a sua obra pela Editora Globo, sediada em Porto Alegre, instaura-se definitivamente o gênero no sul, com o aumento de títulos, edições e também de novos autores.

3. Consulte-se LAJOLO, Marisa \& ZILBERMAN, Regina. Literatura infantil brasileira: história \& histórias. São Paulo: Ática, 1985.p.46. 
No entanto, não fugindo às suas características históricas, a literatura infanto-juvenil surge, entre nós, comprometida com a educação da infância e da juventude. Quando a burguesia urbana se estabelece e a população se desloca do campo para as cidades, as escolas multiplicam-se, exigindo novos materiais de leitura, entre eles a literatura infantil e juvenil. Se no Brasil tal processo acontece no final do século XIX, no Rio Grande do Sul ele é bastante tardio, devido às condições econômicas, sociais e políticas de um território somente anexado ao Reino Português em 1750. Desse modo, apenas na terceira década do século XX o Estado conquista o poder, com Getúlio Vargas no governo central, e, conseqüentemente, entra no compasso do desenvolvimento dos centros mais avançados do Brasil. Abrem-se, então, portas para uma literatura infantil e juvenil, tanto em termos de autores e obras, como de circulação e consumo de livros. Erico Verissimo inaugura o processo e escreve, no bilhete que introduz Aventuras no mundo da bigiene: "O aluno só se entrega de corpo e alma àquele que lhe contar a melhor história de fadas ou aventuras. A estrada mais curta e certa para a inteligência tem passagem obrigatória pelo coração."

Podemos observar que há um destinatário certo para a literatura o aluno. O autor não se refere à criança, ao jovem, ao leitor, mas circunscreve seu receptor no espaço escolar. Daí a preocupação em transmitir conhecimentos, aliando-se à instituição regular de ensino, compromissada com a formação intelectual das novas gerações. A sensibilidade do leitor, através do apelo às emoções que as histórias podem provocar, funciona, por conseguinte, como um meio para a consecução de um alvo extra-literário - a educação. Por educar, Erico entende formar e informar, isto é, importa-lhe transmitir uma visão humanística de mundo, recheada de valores como fraternidade, solidariedade, respeito ao outro e retidão de caráter. Paralelamente, está imbuído da idéia de que é preciso dominarmos o saber letrado, para nos sairmos bem na vida. A experiência da fantasia, por seu turno, completa a proposta do autor, fazendo com que os leitores desenvolvam a capacidade de inventar, vivenciando o mundo mágico das fadas recriadas. Três são, pois, os pilares que sustentam a literatura infantil e juvenil de Erico Verissimo: formação, informação e imaginação.

Nesse sentido, o conhecimento, pois, que os contos infantis e as novelas juvenis de Verissimo veiculam desdobra-se em naturezas diversas. Ele pode ser científico, moralizante ou, simplesmente, fantástico. Nos dois primeiros casos, verificamos a proposição de mudança de comportamento do leitor, quer 
pela aquisição do saber, quer pela assimilação dos valores adultos, mesmo que a aceitação das normas impostas aconteça por conveniência (como em As aventuras do avião vermelho). Subjaz, portanto, nas mensagens dedicadas à infância e à juventude, uma intenção educativa, que credita à aprendizagem a capacidade de promover o crescimento intelectual e moral do sujeito, de modo a torná-lo um adulto mais livre e, ao mesmo tempo, adaptado à sociedade em que vive.

A transmissão do conhecimento científico ou moralizante processase através da leitura de histórias, que o apresentam de formas várias. Ele pode estar contido na representação de mundo que os textos ficcionais encerram, remetendo à determinada organização social, a comportamentos exemplares, a relações entre personagens, a intercâmbios com o espaço exterior. Pode, ainda, estar expresso claramente na voz do narrador onisciente, que retrata a ação para dar informações (como em A vida do elefante Basilio e O urso com música na barriga) ou mescla realidade e ficção (como em A vida de Joana d'Arc). Quando o protagonista, em As aventuras de Tibicuera, relata fatos vividos, aproxima História e fantasia, uma vez que a personagem percorre toda a História do Brasil e pode, portanto, ser a testemunha ocular dos acontecimentos que constroem a nacionalidade. Também o diálogo entre as personagens funciona como transmissor de conhecimento, quando, por exemplo, Fernandinho, em $A s$ aventuras do avião vermelho, pergunta e o pai responde para que serve uma lente. Finalmente, a história pode converter-se, ela mesma, numa situação ficcional de sala de aula, em que um professor transmite o conhecimento a seus alunos. Em Aventuras no mundo da higiene, as lições são dadas a partir de um estímulo, de uma necessidade, de uma oportunidade que se apresenta. O professor é o adulto exemplar, detentor do saber, enquanto as crianças são alunos interessados que atendem às expectativas dos mais velhos.

Ao abordar a questão da educação através da literatura, o autor demonstra estar a par das novas conquistas da Pedagogia. Suas personagens desenvolvem técnicas de ensino fundadas nas experiências do educando, de caráter pragmático, capazes de redundar em melhor qualidade de vida àqueles que aprendem, pois encorajam-se atitudes de formulação de conclusões e aplicação de conhecimentos em novas situações. A autonomia daí advinda permite que, ao contrário do que podemos esperar em textos preocupados com a educação, as noções transmitidas sejam assumidas pelas personagens crianças. Quando isso acontece, é certo que a aprendizagem está garantida de modo satisfatório. 
Os princípios da "nova escola" estão presentes, assim, na idéia de educação a partir da experiência e, o que é importante, de educação universal, para todos, uma vez que a narrativa aproxima crianças de classes sociais diversas no ato comum de estudar. O conhecimento é entendido, pois, como direito ao qual o homem deve ter acesso, indiferentemente de cor, sexo, religião ou casta social. O resultado último é o crescimento das personagens, que introjetam hábitos e normas, ao mesmo tempo em que se desenvolvem intelectualmente, atingindo capacidade de abstração. As reações de Zé Pedro, em Aventuras no mundo da bigiene, em dois momentos distintos da aprendizagem, demonstram o avanço de seu raciocínio simbólico. Observemos-se os fragmentos que seguem:

Professor - O homem invisível era um inimigo terrível porque a gente nunca sabia onde ele estava. Assim também são os micróbios

Zé Pedro - Como é que vamos combater soldados que ninguém vê? Dando tiros neles pelo canudo do microscópio?

Zé Pedro - O senhor diz que devemos azeitar as nossas molas e botar gasolina no nosso tanque?

Como podemos constatar, no início, a personagem percebe apenas o sentido primeiro das palavras, sem conseguir estabelecer relações metafóricas. Mais adiante, além de ser capaz de tirar conclusões, o que denota capacidade de abstração, cria suas próprias metáforas, utilizando-se de linguagem simbólica. Seu amadurecimento lingüístico revela exercício de pensamento mais elaborado, conseqüência, seguramente, das lições vividas e aprendidas.

Em Viagem à aurora do mundo, a situação de sala de aula repetese, embora sem a formalidade de Aventuras no mundo da bigiene. Mas, do mesmo modo, as personagens empreendem uma investida ao mundo do conhecimento, tuteladas pelo cientista que, sugestivamente, desempenha o papel de professor. Através de sessões que simulam a vivência escolar, os assistentes

4. Sobre "nova escola" consulte-se ROMANELLI, Otaíza de Oliveira. História da educação no Brasil. 7.ed. Petrópolis: Vozes, 1985. p.142-152.

5. Verissimo, Erico. Aventuras no mundo da bigiene. Porto Alegre: Globo, 1935. p. 45 .

6. Id. Ib., p. 51 
descobrem o surgimento da vida e da evolução das espécies até o aparecimento do homem na terra. Para tanto, valem-se de moderna invenção, um aparelho capaz de refletir na tela imagens animadas das eras longínquas. A aprendizagem acontece, portanto, de forma experimental, uma vez que há a possibilidade de volta no tempo e percepção do mundo em ação.

A reação dos participantes, descritas pelo narrador-testemunha, em primeira pessoa, varia de acordo com o interesse de cada um, desdobrandose em curiosidade, espanto, ceticismo, incredulidade, entusiasmo e enfado. O autor conquista seu leitor para as mais de trezentas páginas do livro, transferindo para as personagens os possíveis sentimentos daquele. Consciente da possibilidade de entendiar seu destinatário, Erico atribui aos entes ficcionais atitudes de desagrado que, uma vez absorvidas pela história, ficam afastadas do leitor. O texto passa a funcionar, assim, como elemento catártico. Os exemplos abaixo, demonstram esse procedimento:

E se conversássemos agora, sobre o aparecimento da vida na terra?

"Ninguém lhe respondeu. Mas expressões de dúvida, indiferença e indecisão se estamparam em todos os semblantes. Era que fazia calor e a hora preguiçosa convidava à sesta ${ }^{7}$

Tenho um castigo para o fantasma - avançou Aristobolus - Façam o pobre diabo assistir a um espetáculo no santuário com dissertação do professor Calamar e música do maestro Colibri. É pior que cadeira elétrica.

O desfecho da história coincide com o fim do invento que promove o conhecimento. A máquina do tempo, que desfila imagens das épocas passadas, é destruída e, com ela, se esvai a possibilidade de estarmos diante do passado em movimento. Desse modo, a experiência vivida converte-se em mistério. Para decifrá-lo, precisamos recriar essa experiência através da literatura. A obra é, portanto, circular, na medida em que narra uma vivência humana, da qual todas as provas foram eliminadas, exigindo, por isso mesmo, a continuidade da busca do conhecimento pela leitura.

7. VERISSIMO, Erico. Viagem à aurora do mundo. 10.ed. Porto Alegre: Globo, 1980. p.102.

8. Id. Ib., p.261. 
Não há dúvida de que há um projeto educativo na literatura infantojuvenil de Erico Verissimo. No entanto, só ele não sustentaria sua obra. Sabemos que os leitores intuem as intenções do autor e, no caso específico de crianças e jovens, rejeitam aquelas nitidamente pedagógicas. Cúmplice de seus leitores, Erico aposta em situações lúdicas e divertidas, que lhes ofereçam a vida como ela pode ser vivida. Não é por acaso que uma de suas personagens diz que "saber é bom. Mas viver é melhor", 9 pois é justamente a capacidade de criar um universo ficcional em que predominam a aventura e a ação que garante sua permanência. O narrador Tibicuera chega a dizer a seus leitores: "Procurem ler um bom compêndio de literatura. Porque eu vou voltar agora às minhas aventuras."

Erico alia-se ao leitor no gosto da aventura. Sua literatura é, conseqüentemente, uma sucessão de ações, como é possível de detectar já nos títulos de seus livros: as palavras aventura, vida, viagem são constantes, remetendo à idéia de um mundo em movimento, da vida em moto-contínuo. A motivação para a ação surge de um estado de carência inicial, como o descrédito, a monotomia, a necessidade existencial, social ou sobrenatural. O passo seguinte é a busca da aventura como afirmação pessoal. Mesmo em Meu $A B C$, texto que prescinde de trama narrativa, apresentam-se seres em ação: avião, bola, cavalo, dragão preenchem o sentido de deslocamento e mudança.

Na maioria das histórias, é um livro o desencadeador da narrativa, incentivando as personagens à ação, por apontar para atitudes exemplares, em que a aventura é o caminho da descoberta do mundo. Tibicuera não é movido pelo modelo de uma leitura, mas toda a sua trajetória orienta-se no sentido de apropriar-se dos livros: "E a todas essas acontecia algo assombroso: eu me mantinha recolhido no meu canto, apegado aos meus livros."

Ao trazer para o foco das histórias o livro e seus conteúdos animados pelo ato da leitura, o autor volta-se para a própria literatura, em esforço metalingüístico de representá-la, atribuir uma função para as personagens e, por conseguinte, para seus leitores e torná-la, assim, objeto de atenção e reflexão. Em outras palavras, livro e leitura desautomatizam-se na vida dos sujeitos, deixam de

9. VERISSIMO, Erico. Viagem à aurora do mundo. 10.ed. Porto Alegre: Globo, 1980. p.285.

10. VERISSIMO, Erico. As aventuras de Tibicuera. Porto Alegre: Globo, 1979. p.146.

11. Ibidem, p.148. 
ser transparentes, para serem definidos como o passaporte da imaginação e da satisfação pessoal.

O espaço da aventura é o desconhecido: a floresta, a França, os lugares além das fronteiras da casa, do chiqueiro, da cidade. A apropriação do mundo é gradativa, em processo de constante adaptação, para o qual contribuem elementos mágicos, como personagens folclóricas e históricas, vozes, personagens de Disney, humanização de conceitos. Em outras palavras, fantasia e realidade convivem harmonicamente na caminhada dos heróis rumo à maturidade.

Assim, a ação desenvolve-se à medida em que as personagens vencem o espaço e crescem porque acumulam experiência. Viver é, em última análise, apropriar-se dos sentidos do mundo, dando uma razão para sua própria vida. O conceito de necessidade da ação está bem definido na trajetória de Joana d'Arc: impulsionada pelas vozes divinas, a guerreira luta até a sagração de Carlos VII e, quando os elementos sobrenaturais a abandonam, ela opta por continuar a batalha. Sua escolha é humana e, mesmo perdendo um a um todos os símbolos bélicos (armadura, capacete, elmo, espada), mantém-se em ação. A continuidade de sua tarefa demonstra que ela é movida não pelos deuses, mas pela própria natureza humana. Talvez essa seja a melhor contribuição de Erico à história da heroína santificada: o realce à sua dimensão terrena, como exemplo do que é capaz o homem movido por suas convicções.

Resolvidos os conflitos, a ordem é recuperada. Às vezes, a volta ao equilíbrio é determinada por uma fuga ou um tombo, indicando o predomínio da voz adulta sobre o interesse do leitor. No entanto, os textos fecham-se propondo novas aventuras, defendendo a idéia de que a fantasia é essencial, mas não devemos permanecer nela. ${ }^{12}$ Precisamos voltar ao real e assumir a vida como ela é. Podemos, contudo, repetir a experiência, pois a fantasia é o alimento da imaginação e da emoção. Não é à toa que o coração de Joana permanece vivo, não se deixando destruir pelo fogo.

Se o professor Salus "é tão habilidoso, tão engraçado e tão bom camarada que é capaz de transformar a mais cacete das matérias num conto

12. Sobre a função da fantasia nas histórias infantis, leia-se BETTELHEIM, Bruno. A psicanálise dos contos de fada. Rio de Janeiro: Paz e Terra, 1978. 
de fadas, numa novela de aventuras", ${ }^{13}$ então Erico Veríssimo é um grande contador de histórias para crianças e jovens, que consegue ensinar privilegiando a ficção e, com isso, garantir o estatuto literário do gênero. Daí sua perenidade e atualidade, expressa nas reedições constantes, que revelam a recepção positiva de seus textos entre o público infanto-juvenil há cerca de setenta anos.

Abstract: Erico Veríssimo wrote eleven books for children and young readers: in 1935 he wrote, A vida de Joana d'Arc [The life of Joan D'Arc]; in 1936, As aventuras do avião vermelho [The Adventures of the Red Airplane], Os três porquinhos pobres[The three little poor pigs]; Rosa Maria no castelo encantado [Rosa Maria in the enchanted castle] e Meu ABC [My ABC]; in 1937, As aventuras de Tibicuera [The Adventures of Tibicuera]; in 1938, O urso com música na barriga [The bearwith music in his belly] and, in 1939, A vida do elefante Basílio [The life of Basílio the bear], Outra vez os três porquinhos [Once again the three little pigs], Aventuras no mundo da higiene [Adventures in the world of hygiene] and Viagem à aurora do mundo [Trip to the dawn of the world]. These works make up a conscious literary project, once the author makes clear what his aim with the young public is and gives a follow up to all his constant reeditions. Erico Verissimo has as his main concerns to educate and inform his readers and, for such an enterprise, he makes use of fantasy as a means of approximation and seduction.

Key words: Erico Verissimo, Literature for Children and Adolescents, Reader Education.

13. Verissimo, Erico. Aventuras no mundo da higiene. Porto Alegre: Globo, 1939. p.15-16. 